\title{
Special section on recommendations and analytics in tourism
}

\author{
Roland Schegg ${ }^{1} \cdot$ Brigitte Stangl $^{2}$
}

Published online: 20 March 2018

(C) Springer-Verlag GmbH Germany, part of Springer Nature 2018

Information and communication technologies (ICTs) are playing a transformational role in travel and tourism. Industry leaders recognise that digital technology is changing rapidly from an efficiency engine to a driver of fundamental innovation and disruption. Research in this area contributes to the understanding of those trends and to the continuous development of strategies and tactics to promote industry competitiveness. The papers published in this section represent extended versions of selected research papers among the many contributions presented at ENTER2017, Information and Communication Technologies in Tourism Conference, which took place in Rome, Italy, on January 24-26, 2017. Organized by the International Federation for IT and Travel and Tourism (IFITT), ENTER offers a unique platform where researchers and practitioners can engage in cutting-edge topics at the intersection of digital technologies and tourism.

While far from being inclusive of all relevant research areas in the field, the collection of seven articles in this special issue provides an interesting view on some of the latest research on applications of ICT in travel and tourism. The contributions span from recommender systems and big data issues (i.e. spatial behavioural patterns of visitors based on location data, reliability of social media data) to the role of cultural and psychological factors in social media conversations and mobile consumer behaviour. Two contributions explore concrete implementation cases of ICT in the travel context, one paper focuses on the use of mobile applications in

Brigitte Stangl

b.stangl@surrey.ac.uk

Roland Schegg

Roland.Schegg@hevs.ch

1 Institute of Tourism, University of Applied Sciences and Arts of Western Switzerland Valais (HES-SO Valais), Sierre, Switzerland

2 School of Hospitality and Tourism Management, University of Surrey, Guildford, UK 
a business travel context whereas a second contribution identifies effective virtual reality (VR) characteristics.

Recommender systems have a long tradition in the tourism and ICT literature (e.g. Ricci 2002; Fesenmaier et al. 2006). Such systems alleviate information overload by straightforwardly suggesting items that are likely to suit users' needs or preferences and have proven to be a valuable means of structuring data and making it easier to access and cognitively process for users (Ricci et al. 2015). The first paper featured in this special issue deals with 'A Chat-Based Group Recommender System for Tourism' and moves from the concept of recommendation systems for individual travellers to propose a new approach for groups of users making joint travel decisions. Authors go beyond the simple use of users' preferences in the recommendation process as they take into account the dynamic of the interactions of users in a real context of a respective group (Nguyen and Ricci-this issue).

The second research 'Strategic Visitor Flows and Destination Management' presented in this special issue provides tools for finding generalised spatial and temporal patterns of tourist movements for a region using big data. Depicting stable and recurring 'Strategic Visitor Flows', abbreviated SVF (Beritelli et al. 2015) in space enables decision-makers within destination management organisations to understand the variety of tourist segments as well as to break free of existing preconceptions on behaviour of tourists. The authors show that using network analysis techniques on passive mobile positioning data is a promising approach for identifying SVFs (Baggio and Scaglione-this issue).

Big data using social media analytics is used in different disciplines. In the travel domain online consumer reviews have been extensively studied as new sources of data to address a range of research questions (see Schuckert et al. 2015 for a review). Despite the popularity of this big data approach among researchers, there has been little discussion and evaluation of the quality of data sourced from social media. Motivated by that lack of evaluation of data quality and the potential limitations of social media data, the third research contribution 'Assessing Reliability of Social Media Data: Lessons from Mining TripAdvisor Hotel Reviews' assessed the reliability of online hotel reviews using text mining (Xiang, Du, Ma, and Fan - this issue).

Social media is also the basis of the fourth research presented in this special issue. While traditional marketing was more a one-way communication of products and services, social media are about interaction and engagement with the customer (Minazzi 2015). Therefore, today customer engagement is seen as a central indicator for measuring the success of organizations' social media efforts (Wozniak et al. 2017); yet, very little is known about the factors that drive it. The article 'Impact of Humour on Firm-Initiated Social Media Conversations' by Ge and Gretzel (this issue) focuses on message characteristics and more specifically the role of humour in encouraging likes, comments and reposts. The paper extends the tourism literature on humour to the social media context and contributes to knowledge on social media affordances and their linguistic relevance.

The fifth contribution included in this special issue, analyses an important yet under-researched issue related to psychological factors that drive and inhibit mobile consumer behaviour. The research presented by Wozniack, Schaffner, StanoevskaSlabeva and Lenz-Kesekamp (this issue) entitled 'Psychological Antecedents of 
Mobile Consumer Behaviour and Implications for Customer Journeys in Tourism' extracts four psychological antecedents of mobile consumer behaviour from a broad range of theories. Factors identified are (1) self-efficacy related to using smartphones and mobile services, (2) mobile-specific innovativeness, (3) mobile users' information privacy concerns, and (4) personal attachment to the smartphone. Conceptual models based on these factors are tested using structural equation modelling on a data set from an online survey with smartphone-owning consumers in Switzerland.

In the sixth contribution featured in this issue entitled 'Business Travellers' Use of Mobile Travel Applications: A Generational Analysis' the authors address the call by previous researchers to focus on emergent transaction channels and communication platforms that could affect different generations by providing a generational analysis of business travellers' use of mobile travel applications (Douglas, Lubbe and van Rooyen-this issue). The target population for this study is South African business travellers that have travelled domestically or internationally. More than 100 functions of mobile applications were tested in terms of the frequency with which they are being used and the likelihood of future use of different generations.

The last research presented in this issue addresses the challenge of designing engaging tourism-related Virtual Reality (VR) experiences. VR applications represent a valid strategy for destination managers in terms of promoting a destination and with regards to communicating memorable experiences. However, measuring effects of VR characteristics such as sound and animation approaches are still a field that requires research particularly in the tourism domain (Guttentag 2010). The article entitled 'Analysis of Heart Rate Data and Self-Reported Perceptions to understand Effective Virtual Reality Characteristics' presented by Marchiori, Niforatos and Preto (this issue) provides insights based on biophysical data i.e. the heart rate, and a survey comprising self-reported perceptions of users actually engaging in a VR experience.

A special thanks goes to all authors, who have contributed their knowledge and research to this special issue, and to all the reviewers who helped to provide feedback for the papers and their contribution to further improve the articles.

\section{Guest Editors}

Roland Schegg

Brigitte Stangl

\section{References}

Beritelli P, Reinhold S, Laesser C, Bieger T (2015) The St. Gallen model for destination management. IMP-HSG, St. Gallen

Fesenmaier DR, Wöber KW, Werthner H (eds) (2006) Destination recommendation systems: behavioral foundations and applications. CABI, Wallingford

Guttentag DA (2010) Virtual reality: applications and implications for tourism. Tour Manag 31(5):637-651 
Minazzi R (2015) Social media marketing in tourism and hospitality. Springer International Publishing, Cham

Ricci F (2002) Travel recommender systems. IEEE Intell Syst 17(6):55-57

Ricci F, Rokach L, Shapira B (2015) Recommender systems: introduction and challenges. In: Recommender systems handbook. Springer, New York, pp 1-34

Schuckert M, Liu X, Law R (2015) Hospitality and tourism online reviews: Recent trendand future directions. J Travel Tourism Marketing 32(5):608-621

Wozniak T, Stangl B, Schegg R, Liebrich A (2017) The return on tourism organizations' social media investments: preliminary evidence from Belgium, France, and Switzerland. Information Technology and Tourism, March 2017, 1-26 